\title{
El transnacionalismo político de los migrantes colombianos en Nueva York y Nueva Jersey (1990-2010): su comprensión desde la óptica de las heridas identitarias y la búsqueda de reconocimiento
}

Constanza Amézquita Quintana*

RESUMEN

Este artículo pretende abordar las dinámicas del transnacionalismo político de los migrantes colombianos en la ciudad de Nueva York y en el área norte de Nueva Jersey durante el periodo 1990-2010, a partir de los procesos de desprecio y sufrimiento moral (estigmatización social) que experimentaron, las implicaciones de estos procesos en la identidad/autonomía de los migrantes (en tanto generadores de heridas identitarias) y su búsqueda de reconocimiento social. El artículo inicia con una caracterización general de la migración colombiana a dicho contexto. Posteriormente, aborda las experiencias de desprecio moral afrontadas por los migrantes en los contextos de origen y destino para la época en mención. Mientras que en el contexto de origen tales experiencias estuvieron vinculadas a la polarización social y política, las violencias, la inequidad y a fuertes impedimentos para la movilidad social ascendente, en el contexto de destino dichas experiencias estuvieron relacionadas con el estigma del narcotráfico, las dinámicas de racismo cultural, la discriminación por escaso manejo del inglés y por la ausencia de un estatus migratorio legal. Por último, el artículo aborda la participación y la

* Doctorado en Estudios Políticos y Relaciones Internacionales de la Universidad Nacional de Colombia, Bogotá (Colombia).camezquitaq@unal.edu.co

Recibido: 30 de marzo de 2015 / Modificado: 27 de junio de 2015 / Aceptado: 28 de junio de 2015.

Para citar este artículo

Amézquita, C. (2015). El transnacionalismo político de los migrantes colombianos en Nueva York y Nueva Jersey (1990-2010): su comprensión desde la óptica de las heridas identitarias y la búsqueda de reconocimiento. OAsIs, 21, 81-107. DOI: http://dx.doi.org/10.18601/16577558.n21.05 
movilización (principalmente a nivel informal y colectivo) de los migrantes en relación con su búsqueda de reconocimiento social.

Palabras clave: transnacionalismo político, heridas identitarias, desprecio moral, búsqueda de reconocimiento, migrantes colombianos.

\section{The political transnationalism of Colombian migrants in New York and New Jersey (1990- 2010): Its understanding from the optics of identity wounds and the search for recognition}

\section{ABSTRACT}

This article aims to understand the dynamics of the political transnationalism of Colombian migrants in New York City and the northern area of New Jersey during the 1990-2010 period from the processes of contempt and moral suffering (social stigmatization), the implications of these processes in the migrants' identity/autonomy (as generators of identity wounds) and their search for social recognition. The paper begins with a characterization of the Colombian migration to that setting. Then it shows the experiences of moral contempt faced by Colombian migrants in the contexts of origin and arrival. In the context of origin such experiences were linked to social and political polarization, violence, inequality and strong barriers to upward mobility, while in the context of arrival these experiences were related to the stigma of drug trafficking, the dynamics of cultural racism, discrimination because of low English proficiency, and the absence of a legal immigration status. Finally, the article discusses the participation and mobilization (mainly at informal and collective levels) of Colombian migrants in relation to the search for social recognition.

Key words: Political transnationalism, identity wounds, contempt and moral suffering, search of social recognition, colombian immigrants.

\section{INTRODUCCIÓN}

La migración de colombianos a Estados Unidos ha ocupado un lugar importante desde la década de los sesenta, dando lugar a la formación de importantes asentamientos en áreas como el sur de la Florida, el condado de Queens en la ciudad de Nueva York y las ciudades de Elizabeth y Hackensack, en el área norte de Nueva Jersey. Ahora bien, un nuevo auge de las migraciones de colombianos a Estados Unidos se relaciona con las condiciones de deterioro de la calidad de vida que el nuevo modelo de desarrollo empieza a generar para importantes sectores de población colombiana, especialmente hacia finales de los años noventa. Para esta época, en Colombia aumentaron los niveles de desempleo e informalidad, situación que se agudizó por efectos de la recesión económica, la aplicación de tecnologías ahorradoras de mano de obra y por el crecimiento de la oferta laboral. Además, una buena proporción de hogares de los sectores medios vio afectada su 
calidad de vida por los crecientes intereses resultantes de la deuda de la compra de vivienda por el sistema UPAC ${ }^{1}$. A tal situación se sumó el incremento de amenazas, secuestros y extorsiones generados por diferentes actores del conflicto colombiano, así como por los grupos de delincuencia común (Díaz, 2008a)².

En consecuencia, para esta época se incrementaron las tasas de emigración de hombres y mujeres profesionales con títulos universitarios, pequeños y medianos empresarios y jóvenes de clase media hacia la ciudad de Nueva York y el área norte de Nueva Jersey, en busca de mejores oportunidades de ingresos y de desarrollo laboral en su campo profesional. La migración a Estados Unidos aumentó y se hizo más compleja y altamente segmentada, ocupando el primer lugar de llegada de los colombianos. De otra parte, se amplió el espectro de los destinos de los colombianos emigrantes hacia Canadá, Europa y Asia. El Valle del Cauca, Bogotá y el Eje Cafetero aparecieron como zonas altamente significativas de expulsión de emigrantes (Díaz, 2008b).

Sin embargo, los perfiles de colombianos que migraron a Estados Unidos durante 1990-
2010 son muy diversos. Muchos de ellos eran trabajadores poco cualificados que huían de áreas golpeadas por la pobreza, mientras que muchos otros eran profesionales que manejaban el inglés y que, en busca de movilidad social, llegaron con una visa de turista; jóvenes de clases medias y media-altas de diversas regiones del país que buscaban realizar sus estudios en el exterior. Otros eran pequeños y medianos empresarios en busca de seguridad y estabilidad; o personas acosadas por su posición de clase o por sus ideas políticas. También se incluían personas de sectores marginados de la sociedad, incluso con antecedentes delictivos: ladrones o asesinos a sueldo $y$, aunque muchos de ellos se habían dedicado en el exterior a otras actividades, algunos continuaban sus carreras delictivas y tenían continuos problemas con las autoridades locales (Guarnizo, 2007; Bidegaín y Aysa, 2006; Díaz, 2008a).

Buena parte de estos migrantes tomaron la decisión de emigrar y escogieron un destino según cálculos individuales en busca de mayores ingresos y de movilidad social ascendente, enfrentando en la mayoría de los casos el descenso de estatus profesional. Otros también

Unidad de poder adquisitivo constante, sistema que nace en 1972, en la búsqueda de la promoción del ahorro privado y la democratización del crédito para vivienda propia.

2 El periodo 1990-2010 se caracteriza por complejas circunstancias económicas, sociales y políticas que van de la mano con elevadas proporciones de migración colombiana a Estados Unidos. En materia económica, durante los ańos noventa se deterioraron las condiciones de vida de buena parte de la población y aumentaron los niveles de pobreza, subempleo y desempleo. Estos fenómenos afectaron principalmente a los sectores medios urbanos y fueron consecuencia de la apertura económica. Aunque a partir del año 2000 la economía comenzó una recuperación que se sostuvo para el resto de la década, las tasas de desempleo y de informalidad se mantuvieron elevadas. En los años noventa, Colombia también experimentó el deterioro de su situación política y social debido a la intensificación del conflicto. Se afianzó además el control territorial y poblacional permanente de grupos paramilitares como estrategia complementaria de la política contrainsurgente de las fuerzas militares. A ello se añade la estrategia militarista ante el conflicto, situación que, aunada al escenario de impunidad, incidió en el aumento de violaciones de derechos humanos, desapariciones forzadas y agresiones contra defensores de derechos humanos, especialmente a partir de 2001. 
migraron por lograr reconocimiento, así como un reposicionamiento personal y familiar en la sociedad de origen (Guarnizo, 2007). En un buen número de casos, "las condiciones de vida y explotación a que están sometidos los emigrantes laborales en su lugar de destino es lo que hace posible que sus familiares en el lugar de origen mejoren sus consumos y, por tanto, las condiciones de sobrevivencia y reproducción a nivel familiar" (Díaz, 2008a, p. 26).

Los colombianos también tomaron la decisión de migrar para escapar de la violencia o inestabilidad política, otros lo hicieron como maniobra familiar para superar la carencia de oportunidades económicas y políticas o vieron en la migración una contribución al desarrollo de la sociedad de origen mediante la transferencia de capital y tecnología. Así, la decisión de emigrar y el destino seleccionado, la forma de incorporación laboral y social en la sociedad receptora, y las relaciones que el migrante conserve con su lugar de origen, distan de ser simples tomas de decisión individuales autónomas o resultados de condiciones estructurales a las que el individuo únicamente responde. En vez de ello, son procesos enraizados en múltiples estructuras sociales, económicas y políticas que van del nivel microestructural (relaciones y obligaciones con familiares y relacionados), al mesoestructural (relaciones y obligaciones comunitarias e institucionales), y al macroestructural (contexto de origen y destino de nivel estatal, económico, político y sociocultural). A la vez, estos procesos afectan los factores micro, meso y macroestructurales que condicionaron y originaron la migración en primera instancia (Guarnizo, 2007).
Aunque en la actualidad Estados Unidos constituye el primer lugar de destino de los colombianos en el exterior, se carece de cálculos precisos sobre el tamaño de la población colombiana inmigrante en ese país y, particularmente, en la ciudad de Nueva York y en el área norte de Nueva Jersey. Esto debido a que muchos migrantes salieron de Colombia de manera irregular (por lo que no se registran en emigración del DAS), y a que buena parte de migrantes permanecen en Estados Unidos con estatus irregular y no se naturalizan (situación ante la cual temen suministrar información al censo estadounidense). Así, mientras que para 2005 el DANE estimó en 3’331.107 los colombianos en el exterior, de los cuales 1.179.211 estaban en Estados Unidos, para 2007 el American Community Survey estimó un total de solo 797.000 personas de origen colombiano residiendo en todo el territorio estadounidense. Entretanto, académicos expertos en el tema han señalado que, para finales de la década 2000-2010, la población colombiana irregular ascendía, en promedio, a tres indocumentados por cada persona que vive con documentos regulares.

Como consecuencia, el Gobierno colombiano ha comenzado a ver en los emigrantes potenciales abogados de sus intereses en el exterior y posibles votantes a su favor, ampliando sus derechos políticos. De esta manera, les ha otorgado la posibilidad de contar con la doble ciudadanía y de sufragar en las elecciones para el Senado, tal como lo estipula la Constitución de 1991 (arts. 96, 171 y 176). Adicionalmente, desde finales de los años noventa ha implementado diversos programas con el fin 
de preservar su lealtad hacia Colombia. Sin embargo, desde el 2002 se detecta un cambio importante relacionado con el surgimiento de acciones estatales que vinculan la migración con el desarrollo. Esto se manifiesta en el Plan Nacional de Desarrollo 2003-2006, aprobado por la Ley 812 de 2003. Uno de sus ejes es el programa "Colombia Nos Une", el cual comprende un diseño de políticas públicas destinadas a la población colombiana en el exterior. Más adelante, en 2005 y 2007 se establecieron nuevos lineamientos de gestión de la emigración colombiana relacionados con la planificación del desarrollo, tales como la Ley 1151 de 2007 que expide el Plan Nacional de Desarrollo 2006-2010 (Díaz, 2008b). Además, solo hasta 2009 fue creado el documento CONPES de Política Integral Migratoria (PIM), liderado por el Programa Colombia Nos Une, con el apoyo técnico del Departamento Nacional de Planeación (DNP), y solo hasta 2012 fue creada la política de retorno.

Pese a ello, diversos estudios muestran que la participación de los inmigrantes se ha limitado al ejercicio del voto en los comicios presidenciales colombianos por parte de unos pocos inscritos en los consulados. Entretanto, su participación en las elecciones norteamericanas ha sido escasa, teniendo en cuenta las inconsistencias en los datos en materia de participación, el alto número de colombianos no "naturalizados" en Estados Unidos y la limitación del conocimiento de la política norteamericana a los inmigrantes con mejor dominio del inglés y con doble ciudadanía.

Cabe señalar, además, que algunos estudios sobre el transnacionalismo político colombiano recurren a enfoques que contemplan únicamente la participación electoral (formal) de los migrantes en las elecciones del país de origen o del país de destino. En consecuencia, buena parte de estas investigaciones se limita a mostrar estimaciones basadas en las cifras oficiales disponibles (en su mayoría discontinuas y distanciadas de la realidad) y al discurso político de los países de origen o de destino sobre esta materia. Así por ejemplo, ciertos estudios señalan que los migrantes colombianos participan poco en la política transnacional debido a que una proporción carece de documentos legales, otra de "doble ciudadanía" y a que otro tanto muestra descreimiento en la política colombiana y en la política en general, sin explorar a profundidad casos de vivencias concretas y de trayectorias migrantes. Entretanto, las investigaciones que abordan la participación política de los colombianos en el país de destino solo contemplan su intervención electoral y, por ende, a los migrantes "naturalizados"; esto desde una aproximación cuantitativa, dejando de lado enfoques cualitativos que aborden tanto la participación informal en la política del país de destino como otras categorías de migrantes (no solo los ciudadanos con doble nacionalidad).

Dado el enfoque cuantitativo de varios de estos estudios, se han dejado de lado importantes aspectos, entre ellos, la preocupación por comprender las formas de participación política transnacional de los migrantes colombianos que trascienden la participación en comicios electorales; la posible incidencia -en sus modos de participación política transnacional-de las dinámicas de estigmatización social que afrontan, no solo en el contexto de destino, sino también en el contexto de origen, y el rol 
que juega la búsqueda de reconocimiento en las prácticas políticas transnacionales y en el liderazgo político transnacional.

Este artículo pretende abordar las dinámicas del transnacionalismo político de los migrantes colombianos en la ciudad de Nueva York y en el área norte de Nueva Jersey durante el periodo 1990-2010, a partir de los procesos de desprecio y sufrimiento moral (estigmatización social) que experimentaron, las implicaciones de estos procesos en la identidad/autonomía ${ }^{3}$ de los migrantes (en tanto generadores de heridas identitarias) y su búsqueda de reconocimiento social. Lo anterior debido a la importancia que, en el campo de la migración, tiene el llevar a cabo estudios que, desde una aproximación cualitativa, privilegien el acceso a las vivencias de los migrantes en contextos particulares dentro del campo político transnacional; enriquezcan la mirada del transnacionalismo político desde la óptica de las experiencias de estigmatización afrontadas por los migrantes y su búsqueda de reconocimiento, y reivindiquen las potencialidades de las prácticas políticas transnacionales de carácter informal o no electoral.

Para efectos del propósito señalado, en este artículo se caracterizan las experiencias de desprecio moral que afrontaron los migrantes colombianos en el contexto de origen durante el periodo mencionado, vinculadas a la polari- zación social y política, la inequidad y a fuertes barreras para el ascenso y la movilidad social, así como a múltiples violencias y amenazas de parte de los grupos armados. También se caracterizan las experiencias de desprecio moral que afrontaron los migrantes en el contexto de destino vinculadas al sistema de estratificación social estadounidense, donde la clase social, el fenotipo racial, el estatus de foráneo, la etnicidad, la nacionalidad, el manejo del idioma y el capital cultural crean complejas jerarquías etnorraciales que influencian las oportunidades de vida y las trayectorias futuras de los inmigrantes, en especial de aquellos considerados como "no blancos", indocumentados y latinos. Se muestra, además, cómo estas experiencias de desprecio afrontadas en origen y destino generaron heridas en su identidad al menoscabar su integridad individual o autorreferencia práctica (sus ideas de sí mismos) y al afectar su autorrespeto (el respeto a sí mismos al ver reconocido el valor de la formación de su propio juicio por otros sujetos) y su autoestima (el sentimiento de tener un significado social en una comunidad concreta).

Asimismo, en este artículo se plantea que estas experiencias de desprecio moral que afrontaron los inmigrantes colombianos en origen y destino también dependen de su relación con el capital económico ${ }^{4}$, social ${ }^{5}$ y cultural del que

3 Entendida desde Axel Honneth (1992) como la integridad individual o la autorreferencia práctica (es decir, la conciencia que una persona posee de sí misma), la cual comprende: autoconfianza, autorrespeto y autoestima.

4 Para Bourdieu, el capital no se limita únicamente a su significación económica, pues dejaría de lado todo un conjunto de "propiedades" que los agentes utilizan en su lucha por el poder. Como señala Ansart (1990) "Si se entiende por 'capital' toda energía social susceptible de producir efectos, se deberá considerar toda energía susceptible de ser utilizada (consciente o inconscientemente) por los agentes, de acuerdo con las posiciones que ocupan en determinado campo, 
disponen y, particularmente, de su estatus legal migratorio al llegar a Estados Unidos.

También se muestra que, a fin de curar las heridas identitarias generadas con las experiencias de desprecio moral afrontadas por los migrantes colombianos (en los contextos de origen y destino) durante el periodo 1990-2010, estos desplegaron su búsqueda de reconocimiento social en las prácticas políticas transnacionales. Principalmente, quienes contaban con experiencia política previa desplegaron diversas estrategias orientadas a construir una identidad positiva para sí mismos. Tales estrategias variaron en relación con su experiencia política previa, su orientación político-ideológica, la localidad a la que llegaron (la ciudad de Nueva York o el área norte de Nueva Jersey), su capital económico, social y cultural, su estatus migratorio y su procedencia regional.

Vale la pena destacar que el artículo se basa en una investigación de tipo cualitativo realizada en el área triestatatal de Estados Unidos, en el marco de la tesis doctoral de la autora. El trabajo de campo se desarrolló en cuatro fases: 1) noviembre-diciembre de 2009, 2) junio-julio de 2010, 3) junio-agosto de 2011, y 4) octubre de 2011, tomando como unidad de análisis diversos perfiles de migrantes colombianos residentes en el condado de Queens (Nueva York) y en Hackensack y Elizabeth (área norte de Nueva Jersey) ${ }^{6}$, seleccionados a través de un muestreo cualitativo. De esta forma, se llevó a cabo una intensa observación etnográfica y se aplicaron más de setenta entrevistas a profundidad a migrantes

como instrumento en la competencia social" (p. 101). Podemos entender el capital económico como los recursos materiales a disposición del agente directa e inmediatamente convertibles en dinero; el capital cultural que puede existir en estado interiorizado o incorporado bajo la forma de disposiciones duraderas del organismo, en estado objetivado, bajo la forma de bienes culturales, cuadros, libros, que son resultado y muestra de disputas intelectuales, y en estado institucionalizado bajo la forma objetivada a través de títulos académicos; y al capital social como el conjunto de recursos potenciales o actuales asociados a la pertenencia a un grupo (Múnera, 2005; Ansart, 1990; Bourdieu, 1997).

5 En el caso del inmigrante colombiano en Nueva York y Nueva Jersey, la importancia del capital social se refleja en el rol fundamental de apoyo que cumplen los familiares o amigos, brindándole alojamiento o ayudándole a conseguirlo, junto con trabajo y documentos de identidad; en algunos casos, el deseo de volver a ver a los seres queridos se convierte en uno de los factores que motiva la migración (reunificación familiar).

6 Particularmente, se trabajó con los colombianos y colombianas que, habiendo emigrado a Queens y al área norte de Nueva Jersey durante el periodo 1990-2010, aún residían en dichas áreas y cumplían con las siguientes características: a) presentar al momento de la entrevista distinto estatus legal migratorio (irregulares, residentes permanentes y dobles-ciudadanos), b) preferiblemente, haber tenido más de 18 ańos al momento de migrar (primera generación de inmigrantes), y c) haber migrado por motivos de seguridad (habiendo o no solicitado asilo político en Estados Unidos) o por razones económicas. Cabe seńalar que el condado de Queens (especialmente el vecindario de Jackson Heights, conocido como "el barrio colombiano") y el área norte de Nueva Jersey (principalmente la esquina del noreste que incluye los condados de Passaic, Hudson, Essex y Union) han agrupado tradicionalmente la mayor proporción de colombianos residentes en el área triestatal. Por ende, la muestra cualitativa de migrantes colombianos seleccionada comprende a un grupo socioeconómico particular (sectores medios de la población latina y de nuestros migrantes) y deja por fuera ciertos perfiles socioeconómicos más altos, entre ellos sectores que manejan muy bien el inglés, de generación 1.5 o segunda generación que se han logrado asimilar con el grupo anglo. 
colombianos en dichas áreas, y a líderes de organizaciones políticas y socioculturales de colombianos. El diseño metodológico de este estudio también dio mayor énfasis a las prácticas políticas no electorales o informales y a los procesos colectivos.

\section{LA MIGRACIÓN Y LAS HERIDAS IDENTITARIAS}

Durante 1990-2010, los migrantes colombianos en estas áreas afrontaron experiencias de desprecio moral (estigmatización) - en los contextos de origen y de llegada- que generaron en ellos fuertes sentimientos de inseguridad ante el persistente temor a la falta de respeto moral o, en otros términos, ante la posibilidad de que los otros pudiesen definirlos en función de su estigma. Dichas experiencias de desprecio moral estuvieron vinculadas, principalmente, a factores como su capital económico, social y cultural, su estatus migratorio y su procedencia regional (esta última en estrecha relación con la composición regional de la colonia colombiana de las localidades a las que llegan). Estas experiencias de desprecio generaron en ellos el sentimiento de no poseer el estatus de sujeto con igualdad moral de derechos y con pleno valor.

En relación con el contexto de origen, los migrantes colombianos experimentaron la polarización social y política en Colombia. Muchos de ellos afrontaron la inequidad y los impedimentos para la movilidad social ascen- dente. Otros afrontaron experiencias asociadas a violencia y amenazas de parte de los grupos armados.

\section{Inequidad y barreras para la movilidad social ascendente en contexto de origen}

Buena parte de los migrantes entrevistados en Queens, que migraron con visa de turista, relatan haber experimentado en Colombia fuertes barreras económicas para su movilidad social ascendente. Vivieron los efectos de la recesión económica de finales de los años noventa y principios del 2000, entre los que se destacan elevados niveles de desempleo, bajos salarios, informalidad y fenómenos como la "jubilacion anticipada" . Así lo confirmó Esmeralda, madre soltera de tres hijos, quien laboró en el mercado informal colombiano y quien, para la época en que decide migrar, experimentó la crisis del UPAC, enfrentándose a la posibilidad de perder su apartamento y de no poder sufragar el estudio de sus hijos:

Yo era madre comunitaria en Colombia y madre soltera y como se dice "todera"; vendía repuestos de carros, vendía cosméticos, cuidaba niños aparte del jardín para poder pagar las cuotas del apartamento y el estudio de mis hijos. Fui madre comunitaria por cuatro años y ya debía cinco cuotas atrasadas del apartamento, me lo iban a quitar... entonces tomé la decisión de venirme [para los Estados Unidos] [...] [En Colombia] si conseguía para una cuota (era un sacrificio) [pero] si se presentaba un gasto, que se me enfermó uno de los niños o si había que comprar uniformes no podía

La exclusión del mercado laboral de los adultos de más de 40 años de edad y su reemplazo por personas más jóvenes. 
pagar la cuota ese mes, entonces se me fueron acumulando las cuotas y ya me iban a quitar el apartamento. [Cuando me vine mi hija] la mayor tenía 17 años, ella quería estudiar y yo quería darle la oportunidad de que estudiara, ella cuando yo me vine estaba terminando el bachillerato y yo quería apoyarla, si no se me habría quedado sin estudiar (Esmeralda, 2011).

En su relato, Esmeralda señaló además su preocupación sobre el fenómeno de la "jubilación anticipada" en Colombia, identificándolo como otra de las barreras que enfrentan los adultos para vincularse al mercado laboral y comparando esta situación con el contexto norteamericano, en el que ella siente tener aún muchas posibilidades de continuar siendo productiva:

Lo malo de Colombia es que uno a los 30 años ya no consigue un trabajo porque lo consideran viejo; ellos [los empleadores colombianos] no miran la experiencia que pueda tener una persona, solo la edad [...] Son muchas barreras [las que hay en Colombia] que uno dice yo me voy a Colombia y con mi edad, tengo 53 ańos, ¿en qué podría trabajar en Colombia? Aquí todavía hay gente de 65 años que todavía va a limpiar casas. Y en Colombia hay gente que incluso tiene sus títulos y que no ha podido ubicarse laboralmente (Esmeralda, 2011).

Otro testimonio representativo es el de María Clara, quien destacó la escasa remuneración percibida como docente en el sector público en Colombia, así como las barreras que encontraba para su movilidad social ascendente:

Yo tenía trabajo pero nunca tuve un buen salario porque en un colegio como profesor oficial uno no pa- sa nunca de un millón cien, un millón doscientos y lo completaba con las clases en las universidades y las conferencias los fines de semana; entonces ahí cuadraba yo la plata. Teníamos un apartamento pequeño en chapinero y sobrevivía al ras pero ya estaba pensando en que mi hija fuera a una buena universidad, entonces aunque yo estaba afiliada a las cooperativas y sabía que iba a hacer un préstamo para eso, yo sí dije: en Estados Unidos va a tener otra oportunidad (María Clara, 2011).

\section{Violencia y amenazas de parte de los grupos armados en el contexto de origen}

Los migrantes entrevistados también relataron haber enfrentado el deterioro de la situación política y la generalización de las violencias (común, de la droga, política) durante el periodo 1990-2010 en Colombia, con el consecuente incremento de la inseguridad. De este modo, muchos de ellos experimentaron amenazas/extorsiones/ataques de parte de los grupos armados debido a su participación en diversas actividades políticas. Por ejemplo, un líder comunitario del área norte de Nueva Jersey relató cómo ante su trabajo comunitario en Colombia -apoyando al partido conservador- recibió amenazas y fue víctima de la persecución de las FARC y de asesinatos de miembros de su familia, al punto que tales hechos motivaron su decisión migratoria:

Me dijeron dentro de 15 días hay que venir por usted; en 15 días yo voy a bajar y no esté aquí; váyase. El guerrillo pues ¿qué me dijo? que la FARC me iban a matar y bueno listo, entonces ya sabe, no vuelva más a esta casa, vaya para otro lado y piérdase [...] Entierro a mi tío, entierro a mi mamá, mando a mi hermano al exterior y a la una de la mańana me estaba sonando el teléfono: el próximo vas a ser vos (y eran 
esos teléfonos viejos que uno no sabe quién lo llama), me voy a trabajar, llego a medio día, abro la puerta de mi apartamento: un sobre grande, abro... un sufragio con mi nombre (Ignacio, 2011).

Por otra parte, debido a su trayectoria familiar o personal de participación en actividades sindicales y de defensa de derechos humanos, una buena proporción de migrantes experimentó persecución y estigmatización, así como distintos tipos de violencia por parte de grupos paramilitares. Esto se refleja en el relato de David, un líder sindical:

Casi siempre estuve envuelto en política porque yo tuve un tío, recuerdo que tenía como 7 años y el lideró una invasión a unos terrenos baldíos cerca a la finca de mi abuelo. Eran como unas 60 familias. Yo visitaba a mi tío más en la cárcel que en la casa. Ellos se metían a esos terrenos, los sacaban de allá, los metían en la cárcel y ellos volvían y se metían allá. Ellos lograron que les dieran títulos de esas tierras, pero a mi tío lo desaparecieron en el año 87 pero nunca encontramos el cuerpo. Entonces desde ahí yo estaba muy joven y desde ahí comencé a envolverme en lo que estaba pasando en el país (David, 2011).

En sus testimonios, los migrantes subrayan también la expansión de la "cultura" del narcotráfico, la delincuencia común y la corrupción estatal como factores que incidieron en su decisión migratoria. De este modo, se destacan testimonios como el de María Clara, docente del sector oficial que migró a finales de la década de los noventa y manifestó su preocu- pación ante lo inadecuado que, a su modo de ver, resultaba el ambiente colombiano para la crianza de su hija adolescente: "Me asustaba un montón que una niña joven [estuviera expuesta a] tanto narco, tanta violencia y cosa fea, no me gustaba que mi hija fuera a estar expuesta a eso" (María Clara, 2011).

Esmeralda, quien migra a finales de la década de los noventa a la ciudad de Nueva York, destacó la inseguridad que experimentó mientras vivía en Colombia y que aún en la distancia experimentaba a través de los relatos de sus hijos y familiares:

Es un temor con el que vive uno, que a qué horas lo van a robar, a atracar y que ojalá los vecinos no se vayan a enterar que la mamá está acá porque pensaran que la mamá es millonaria, entonces son como muchos temores, muchas cosas con las que vive uno en Colombia (Esmeralda, 2011).

Por otra parte, Sergio, un antiguo líder de una de las principales organizaciones profesionales de colombianos en el exterior, quien migró a inicios de la década de los noventa a la ciudad de Nueva York, destacó el impacto que, entre la población, tenían las barreras para la movilidad social en el país:

Colombia es un país artificial, un país sitiado por la guerrilla y que sale adelante a través de su cleptocracia con el narcotráfico y con algunas estaciones norteamericanas. Sin esas ayudas a Colombia le hubiera tocado dialogar con la guerrilla porque diálogos nunca hubo, sino una payasada tanto de los dos y engañaron

8 Se refiere a las negociaciones Gobierno-FARC en San Vicente del Caguán a finales de la década de los noventa. 
a Colombia, cada uno por su negocio ${ }^{8}[. .$.$] Yo hablo$ con mis amigos, colegas que viven en Cali y hablo de las posibilidades y todo mundo es con un pesimismo y la gente ya perdió como la esperanza de que las cosas se puedan hacer bien y la gente aplaude a los que hacen las cosas bien pero no les importa el proceso por el que se logró [...] En Colombia se corre la idea de que todo vale sin importar los medios (Sergio, 2010).

Ahora bien, a su llegada a Estados Unidos estos migrantes enfrentaron el estigma del narcotráfico y la imagen de Colombia en el exterior vinculada a este flagelo y a la violencia; estigma que generó heridas en su identidad nacional como colombianos. Allí muchos de ellos percibieron que el Estado colombiano los veía como generadores de remesas y de lobby político a favor de los intereses de la institucionalidad. En adición a ello, buena parte de los migrantes afrontó experiencias de desprecio relacionadas con dinámicas de racismo cultural y discriminación por su escaso manejo del inglés y por la ausencia de un estatus migratorio legal.

\section{Estigmatización de los migrantes colombianos en tanto migrantes y Latinos}

En Estados Unidos, los migrantes colombianos se desenvolvieron en medio de un sistema de estratificación donde, además de la posición ocupada en el mercado de trabajo, el fenotipo racial (ser identificado como "blanco" o "no blanco”), el estatus de foráneo (y en este caso el país de origen $)^{9}$, la etnicidad y la nacionalidad crean complejas jerarquías etnorraciales que influencian las oportunidades de vida y las trayectorias futuras de los inmigrantes, en especial de aquellos considerados "no blancos". Ante su condición de inmigrantes, este sistema establece barreras para su movilidad económica y social, considerando que se desenvuelven en un mercado de trabajo segmentado entre un sector primario (intensivo en capital, oficios altamente calificados, equipo avanzado, estabilidad laboral y salarial) y un sector secundario, con escasa inversión de capital, oficios poco cualificados y condiciones de trabajo y salario inestables, desempeńados en su mayoría por migrantes latinos, particularmente indocumentados, quienes experimentan mayor precariedad en derechos y beneficios sociales (Cordero-Guzmán et al., 2001).

Los colombianos entrevistados manifestaron haber experimentado formas sutiles de discriminación en el ámbito laboral y en la interacción cotidiana con ciudadanos norteamericanos debido a su origen latino. De este modo, Fabio, un colombiano que migra a los 16 ańos con su familia a la ciudad de Nueva York, destacó, desde su experiencia, que en su trayectoria laboral se sintió constantemente presionado para demostrar sus resultados mucho más que un ciudadano norteamericano promedio:

En mi trabajo, yo he visto por ejemplo que a la gente latina la convocan para ciertos trabajos profesio-

$9 \quad$ Los inmigrantes de países como Cuba fueron ampliamente bienvenidos por razones ideológicas como aliados en la Guerra Fría, mientras quienes contaron con menor probabilidad de recibir una bienvenida oficial fueron los migrantes indocumentados, quienes ingresaron al país sin autorización, violaron los términos de una visa temporal de trabajo o permanecieron sin permiso (Massey y Sánchez, 2010). 
nales, no sé si son las calificaciones que la comunidad latina presenta, pero tratan mucho para contratarlos para posiciones administrativas pero no los ve de supervisores o de gerentes. Eso era lo que yo trataba de hacer y casi me meto en problemas por querer escalar en el trabajo, siempre uno está puyando para cambiar de puesto, no de salario, pero sí que lo manden a otro departamento y es así o se va. [Por otra parte], la cuestión [de la discriminación] aquí en Nueva York se maneja muy sutilmente, que yo me haya sentido discriminado abiertamente no. Pero sutilmente sí lo he sentido, uno lo puede sentir en las relaciones en el trato diferente de las cosas... una vez iba por una calle y yo me le atravesé a alguien y me gritó un epíteto absolutamente racista. Uno entiende que el país está segmentado no solamente en cuestión de razas sino también étnicamente y en la parte sociocultural. Dentro de la comunidad latinoamericana también hay otro dinamismo de racismo, de clasismo, a diferente nivel (Fabio, 2011).

Por otra parte, Hernán, un líder sindical colombiano en la ciudad de Nueva York, que migró a principios de la década de los noventa, destacó su percepción sobre la discriminación que experimentan los migrantes latinos en el ámbito laboral: "No hay inmigrante latino que no sienta la discriminación en el trabajo. Por parte del idioma [el hecho de) que uno no pueda acceder a ciertas cosas, que necesite traductores para ciertas cosas, eso es un sentido de vulnerabilidad [social]” (Hernán, 2011).

\section{La estigmatización de los colombianos en tanto hispano-parlantes ${ }^{10}$}

De acuerdo con Vilma Santiago-Irizarry, el lenguaje es uno de los principales marcadores de identidad para las comunidades latinas, pero ha sido erróneamente direccionado dentro del terreno monolingüe inglés de Estados Unidos (Santiago-Irizarry, 2001). A pesar de su vitalidad expresiva, significancia cultural, ubicuidad local y validación oficial, el bilingüismo latino y los modos multidialécticos de hablar español permanecen estigmatizados en la ciudad de Nueva York. Aunque esta ciudad fue el primer espacio urbano donde los enclaves panlatinos se han (re)constituido mejor como poderosos actores socioculturales, muchos de los signos públicos en español presentes en la ciudad no han sido pensados como expresiones de inclusión ni de empoderamiento de las comunidades latinas, así como tampoco están basados en un reconocimiento de la paridad cultural. Por el contrario, han sido pensados como dispositivos ordenadores para las interacciones instrumentales de la vida diaria. Algunos de estos signos son el resultado de procesos político-legales de reivindicaciones y negociaciones en ciertas áreas, mientras otros han sido creados para convertir a los latinos

10 Vale la pena destacar que dentro de los migrantes colombianos residentes en el área triestatal hay un sector que maneja muy bien el inglés, que escapa a este tipo de discriminación y que se ha logrado asimilar con éxito al grupo anglo (por ejemplo, los colombianos que trabajan en Wall Street). Sin embargo, este sector no fue incluido en la muestra cualitativa de migrantes colombianos seleccionada para este estudio (ver nota al pie 7). 
en consumidores de servicios y productos del capitalismo corporativo (Irizarry, 2001).

Pero este estatus subordinado del espańol en el contexto norteamericano obedece además a un contexto cultural permeado por inequidad de condiciones en donde, pese a los actuales reclamos a favor del multiculturalismo y de la pluralidad, prevalecen ideologías y prácticas monoculturales y monolingües que sitúan al inglés como lengua de prestigio (Irizarry, 2001).

Independientemente de su nivel de inglés, los migrantes colombianos entrevistados manifestaron haber experimentado discriminación en tanto hispano-parlantes debido a su acento latino y a su falta de fluidez o de comprensión de la lengua. Para los migrantes de primera generación, esto limitó su interacción tanto con anglo-parlantes como con instituciones públicas, agencias oficiales y de servicios sociales y otras entidades públicas. Por ejemplo, muchos no sabían que contaban con el derecho a solicitar ayuda de traductores oficiales. Así lo relató "pecas", quien migró a principios del 2000 sin saber inglés y con visa de turista:

[Para mí fue terrible] la falta de inglés, no de los papeles como tal pero la falta de inglés sí, porque por ejemplo uno va a un hospital y están muy afanadas las secretarias o esas señoras que trabajan dentro de un hospital y uno no entiende o algo así y entonces tras de que no tiene papeles ¡no sabe inglés! [...] Por ejemplo, le dicen a uno. Pero entonces hay una tabla que dice que si uno no sabe inglés a uno le llaman a un intérprete, pero entonces uno no hace valer eso, porque no sabe (Pecas, 2011).
De otro lado, esta falta del idioma dificultó a los migrantes interesarse en la política norteamericana, ampliar su conocimiento de cultura política y, en consecuencia, participar en ella.

Otros migrantes señalaron haber sufrido cierta discriminación a causa de su acento latino al hablar inglés en espacios que compartían con anglo-parlantes, pese a contar con un fenotipo que no les permitía ser identificados inicialmente como latinos. Así por ejemplo Rebeca, quien migra en la década de los noventa, procedente del eje cafetero: “A mí me aceptaban por el fenotipo pero si abría la boca me rechazaban" (Rebeca, 2011).

\section{La estigmatización de los colombianos como narcotraficantes}

La participación de Colombia en el narcotráfico, junto con la presión policial en su contra, llevó a los colombianos en la ciudad de Nueva York y el área norte de Nueva Jersey a experimentar una aguda estigmatización. Durante el periodo considerado, pero con especial fuerza en las décadas de los ochenta y noventa, los colombianos fueron vistos como personas potencialmente peligrosas, poco confiables y asociadas con la delincuencia y el crimen organizado de los carteles de droga. $\mathrm{Al}$ decir de una migrante colombiana en el área:

El estigma sigue, tu todavía dices yo soy colombiano y lo primero que te preguntan es: ¡Ahh! ¿Eres colombiano?, ¡humm! Y lo primero que se le viene a la persona a la mente es droga o la guerrilla. Infortunadamente, algunos colombianos lo hicieron [narcotráfico] 
y aún lo hacen pero son unos pocos y eso es lo que sale por las noticias (Derly, 2011).

$\mathrm{Al}$ respecto, vale la pena señalar que en las entrevistas realizadas a migrantes, muchos de ellos señalaron haber negado o escondido su nacionalidad colombiana ante estadounidenses en contextos de trabajo, estudio o entretenimiento. Otros señalaron que entre las "bromas imperdibles" jugadas por parte de los estadounidenses o de otros latinos en contextos cotidianos estaban el asociarlos al narcotráfico preguntándoles por ejemplo si eran familiares de Pablo Escobar, si portaban cocaína o si podían indicarles dónde comprarla. "Pecas", una colombiana que migra a la ciudad de Nueva York a principios del 2000 señala la pervivencia del estigma de narcotráfico sobre los colombianos, el cual ella experimentó, principalmente, al buscar vivienda: "si eras colombiana nadie te quería rentar porque todo lo relacionaban con droga” (Pecas, 2011).

\section{Privación de derechos y marginación social en los residentes e irregulares}

En Estados Unidos, el aspecto "legalizador" ubica a los migrantes "regulares" (residentes permanentes y ciudadanos) por encima de los "irregulares". Mientras los primeros cuentan con acceso más fácil a los puestos de trabajo y mayor disfrute de derechos (Ribas, 2004), los segundos carecen casi de todos los derechos, excepto de aquellos garantizados por todos por los instrumentos internacionales de derechos humanos. En el proceso de legalización de los migrantes, estos obtienen primero los derechos sociales (el acceso a seguridad social) antes que los derechos políticos (al voto y a participar en los procesos de decisión). Entretanto, los ciudadanos cuentan con más derechos y beneficios sociales que los residentes permanentes ${ }^{11}$ y que los solicitantes de asilo (quienes disponen de derechos muy limitados bajo regímenes especiales).

Dentro de los inmigrantes colombianos en situación de irregularidad entrevistados se incluían aquellas personas de clases medias que habían viajado con visa de turista y se habían quedado una vez esta había expirado, así como personas de extracción popular que habían viajado mediante redes ilegales, afrontando generalmente un proceso de segregación social ("asimilación hacia abajo"). En dicho proceso, las actividades ilegales eran empleadas, muchas veces, para tratar de evadir las trabas estructurales del mercado laboral "legal" norteamericano en busca de oportunidades de mejores ingresos, por ejemplo, mediante documentos falsos o mediante la instrumentalización de las relaciones afectivas con los matrimonios arreglados.

En el caso de los migrantes colombianos indocumentados consultados se generó una inserción en términos de precariedad laboral en el país de destino, en donde el inmigrante desplegaba diversas estrategias para tratar de

11 En especial, después de la implementación, en 1996, de The Personal Responsability and Work Opportunity Reconciliation Act (PRWORA), medida que les prohibió recibir cupones de comida y otros beneficios cinco años después de la admisión. 
evadir las trabas estructurales del mercado laboral "legal" norteamericano en busca de ingresos. $\mathrm{Al}$ respecto, vale la pena mencionar el testimonio de Alfredo, quien pasó de ser empleado en el área de limpieza a montar una empresa en ese campo y a lucrarse de los trabajadores indocumentados debido al ahorro en impuestos que esto le representaba, pues no incluía a estos trabajadores en la nómina normal:

En mi negocio de limpieza yo he manejado hasta ochenta personas, cien personas. Yo manejo normalmente en un día malo diez personas, de muchos países latinoamericanos. Ellos son todos ilegales; uno se las arregla para no tener problemas con ellos. Igual es más barato ese trabajo, uno no mete eso como una nómina normal. Deja uno de pagar unos impuestos que uno debe pagar, pero yo pago un poquito más de lo que pagan normalmente a los ilegales en la ciudad de Nueva York. Tanto yo como mis empleados hacemos evasión de impuestos también, eso es una cosa por otra, es lo que al americano no le gusta, al alto ejecutivo tampoco porque ellos pagan impuestos y los ilegales no (Alfredo, 2009).

\section{LA BÚSQUEDA DE RECONOCIMIENTO A TRAVÉS DEL TRANSNACIONALISMO POLÍTICO}

Como una forma de curar las heridas identitarias generadas con las experiencias de desprecio moral afrontadas por los migrantes colombianos (en los contextos de origen y destino) durante el periodo 1990-2010, estos desplegaron su búsqueda de reconocimiento social en las prácticas políticas transnacionales. Principalmente, quienes contaban con experiencia política previa desplegaron diversas estrategias orientadas a construir una identidad positiva para sí mismos. Tales estrategias variaron en relación con su experiencia política previa, su orientación político-ideológica, la localidad a la que llegaron (la ciudad de Nueva York o el área norte de Nueva Jersey), su capital económico, social y cultural, su estatus migratorio y su procedencia regional.

Por un lado, algunos migrantes colombianos orientaron su búsqueda de reconocimiento hacia las prácticas políticas formales e individuales, a saber, las elecciones del país de llegada y de origen. En el primer caso, participaron quienes disponían de doble ciudadanía y de cierto capital económico, social y cultural que les permitía estar actualizados en materia de política norteamericana. Sin embargo, este tipo de participación fue escasa y no se cuenta con suficientes datos estadísticos que permitan obtener conclusiones certeras sobre este aspecto. Así pues, los datos en materia de "naturalización" de los colombianos en la ciudad de Nueva York y el área norte de Nueva Jersey son parciales e imprecisos (ya que solo están disponibles para ciertos ańos y han sido calculados sobre la base de datos censales los cuales, a su vez, fallan al registrar la totalidad de migrantes colombianos en las áreas mencionadas), así como los datos concernientes a la participación electoral de los colombianos en la política norteamericana.

Para el caso de la participación individual en las elecciones del país de origen, quienes lo hacen no requieren contar con un estatus migratorio legal en el contexto de llegada. Sin embargo, aunque este tipo de participación es un poco mayor que en el caso anterior, predomina el abstencionismo electoral, fenómeno que tie- 
ne lugar en el país de origen ante el desinterés en la política en general y la desesperanza generalizada frente al sistema político. No obstante, el énfasis de este apartado no radica aquí, sino en las estrategias de búsqueda de reconocimiento orientadas hacia las prácticas políticas informales y colectivas que trascieden el voto ( $y$ que permiten a los inmigrantes ser reconocidos sin necesidad de ser ciudadanos ni de votar). Por eso, dentro de las prácticas políticas informales analizadas se tuvieron en cuenta las maneras que encontraron los migrantes colombianos para defender sus derechos, los espacios de participación política de carácter informal en donde fueron capaces de tener impacto en la política local estadounidense y en la colombiana, $y$ algunas de las estrategias alternas al voto para ejercer presión sobre las políticas locales y transnacionales.

Por ende, los migrantes colombianos movilizados de esta manera no requirieron tener ciudadanía o estatus migratorio legal (como residentes) y emprendieron su búsqueda de reconocimiento mediante su participación / vinculación en organizaciones colombianas, aprovechando con ello su capital social o buscando incrementarlo. El carácter de las organizaciones a las que se vincularon en dicha búsqueda de reconocimiento dependió principalmente de su experiencia política previa, su orientación político-ideológica, la localidad a la que llegaron (la ciudad de Nueva York o el área norte de Nueva Jersey), su capital económico, social y cultural, su estatus migratorio y su procedencia regional. Pero algunos factores (entre ellos la desconfianza generada por el estigma del narcotráfico, el clasismo y regionalismo colombiano, la polarización social y política, así como las huellas del conflicto armado) incidieron en que las organizaciones generadas por los migrantes terminaran reproduciendo la fragmentación existente en el país de origen. De este modo, dichas organizaciones terminaron operando en dos grandes niveles: 1) apoyo a iniciativas, discursos y políticas del Gobierno colombiano y lucha contra el estigma del narcotráfico y la violencia, y 2) apoyo a iniciativas de defensa de derechos humanos. En consecuencia, la búsqueda de reconocimiento de los migrantes que participaron en dichas organizaciones reprodujo la polarización existente en Colombia.

\section{Apoyo a iniciativas, discursos y políticas del Gobierno colombiano y lucha contra el estigma del narcotráfico y la violencia}

Buena parte de los migrantes movilizados aquí contaba con experiencia política previa (familias con alto grado de involucramiento en la política, habían participado activamente en organizaciones / partidos, comités de apoyo político en el país de origen o en organizaciones de carácter profesional). En materia de orientación político-ideológica, manifestaron su favorabilidad -en mayor o menor grado-hacia la intervención militar del Estado colombiano en el conflicto armado (pero hacia su poca intervención en la economía) y hacia la negación de estatus político a las FARC después del 9-11.

En su mayoría, estos migrantes afrontaron experiencias de desprecio en su país de origen relacionadas con violencia de parte de los grupos armados (amenazas / extorsiones por parte de la guerrilla) e inequidad (barreras para el ascenso / movilidad social). También afrontaron experiencias de desprecio en el país de llegada 
relacionadas con racismo cultural, discriminación por el escaso manejo del inglés y por la ausencia de un estatus migratorio legal, así como por el estigma del narcotráfico. Sin embargo, un factor clave para que los migrantes se movilizaran a favor de iniciativas, discursos y políticas del Gobierno colombiano radicó en haber afrontado violencia ejercida por grupos insurgentes de izquierda. Así se observó en diversos testimonios encontrados.

A su llegada a Estados Unidos, estos migrantes afrontaron el estigma del narcotráfico y la imagen de Colombia en el exterior asociada con narcotráfico y violencia de parte de grupos armados, lo cual generó heridas en su identidad nacional como colombianos. Al tiempo, muchos de ellos percibieron que el Estado colombiano los veía como generadores de remesas y de lobby político prointereses de la institucionalidad. Así, por ejemplo, Rodolfo, uno de los exlíderes de una de las organizaciones profesionales en la ciudad de Nueva York que migró en la década de los noventa, afirmó:

Los colombianos en el exterior no cuentan, es más, se ven como enemigos. Hubo algún momento en Colombia en que no pararon de demonizar a los colombianos en el exterior como los apátridas que abandonaron el país en los momentos de crisis y lo que pasa es que para mí el concepto de nacionalidad se ha transformado. Colombia no es el territorio, Colombia es su gente, porque el territorio existe hace millones de años pero quien hace a Colombia es su gente. Si yo soy colombiano, yo soy Colombia en el exterior (Rodolfo, 2011).

En consecuencia, al sentirse olvidados por parte del Estado colombiano y al relacionarse cotidianamente con el estigma del narcotráfico y la violencia, estos migrantes encontraron que una manera de ser reconocidos por la institucionalidad colombiana (y de tratar de curar esa herida identitaria relacionada, en este caso, con su identidad nacional) era mediante su participación en actividades por el buen nombre del país y de los colombianos en el exterior, contribuyendo así a difundir una imagen más positiva de Colombia. Por esta razón, muchos de ellos se organizaron / movilizaron para defender los intereses del Estado colombiano ante el Gobierno norteamericano y para apoyar / difundir los discursos y las políticas del Gobierno colombiano mediante su vinculación en organizaciones cívicas, socioculturales y profesionales. Para ello, emplearon diversas estrategias, entre estas foros académicos, conferencias, seminarios y exposiciones artísticas orientadas a difundir una imagen más positiva del país; marchas de protesta hacia los grupos armados en Colombia y a favor del Gobierno; fiestas y desfiles de independencia; reuniones periódicas y contacto constante por medios virtuales, así como actos de filantropía y solidaridad frente a desastres naturales en Colombia.

En estos migrantes, la noción de identidad nacional colombiana estaba muy arraigada. Sin embargo, hay una diferencia importante entre los migrantes que residían en la ciudad de Nueva York (particularmente en los distritos 21 y 25 del condado de Queens) y en el área norte de Nueva Jersey (sobre todo en las ciudades de Hackensack y Elizabeth), así como entre los migrantes procedentes del interior del país y los migrantes provenientes de la costa Caribe colombiana, a saber: en los colombianos que residían en el área norte de Nueva Jersey 
y los oriundos de la costa caribe se observó una ampliación de la noción de identidad hacia una identidad latina. Ello debido a que percibieron las formas de racismo cultural reproducidas por los colombianos del interior ${ }^{12}$ así como su cercanía cultural con otros migrantes caribeños (quienes a su vez representaban la mayor población latina en las áreas consideradas y dominaban los cargos/instituciones latinas).

\section{Apoyo a iniciativas}

\section{de defensa de derechos humanos}

Buena parte de los migrantes colombianos movilizados a favor de la defensa de los derechos humanos en Colombia, contaba con experiencia política previa en los sectores de izquierda (partidos, movimientos o sindicatos); otros eran familiares de militantes de sectores de izquierda y del partido liberal, así como de activistas de derechos humanos. Al igual que en el caso de los migrantes movilizados a favor de las iniciativas gubernamentales, vemos que el capital cultural ${ }^{13}$, la generación y el estatus migratorio presentaban una gran diversidad, por lo que no son variables relevantes para comprender la movilización a favor de estas iniciativas.
Por el contrario, una variable importante para dicha comprensión es el haber afrontado experiencias de desprecio en su país de origen relacionadas con violaciones de derechos humanos (haber sido testigos de diferentes tipos de violencias por parte de grupos armados, persecución y estigmatización) e inequidad (barreras para el ascenso/movilidad social). Así, entre los migrantes movilizados por la defensa de los derechos humanos y en oposición a las políticas gubernamentales en Colombia, fue frecuente escuchar testimonios que relataban experiencias en las que habían sido víctimas de persecución o de violencia de Estado o de grupos paramilitares o, también, de estigmatización por su actividad política, comunitaria o de defensa de derechos humanos.

A su llegada a la ciudad de Nueva York y al área norte de Nueva Jersey, estos migrantes afrontaron el estigma del narcotráfico y la imagen del país en el exterior asociada con narcotráfico y violencia. Esto les generó heridas en su identidad nacional colombiana. Adicionalmente, afrontaron experiencias de disciminación en tanto latinos (racismo cultural), ocupando en buena medida aquellos empleos peor remunerados y con escasas garantías laborales, así como experiencias de discriminación por el escaso manejo del idioma inglés.

\footnotetext{
12 Colombia presenta una historia de conquista y colonización que ha contribuido a la formación de jerarquías sociales, a menudo basadas en distinciones raciales y étnicas, pero también en distinciones de clase, "raza” y "región”. Así que buena parte de los inmigrantes colombianos procedentes del interior del país migran hacia Queens (en Nueva York), donde reproducen sutiles formas de racismo cultural frente a quienes proceden de las costas -y áreas aledañas-, refiriéndose a ellos con los términos de "parranderos", "bullosos" y "perezosos para el trabajo".

13 Se incluyen tanto migrantes con estudios profesionales en Colombia que continuaron sus estudios en Estados Unidos y manejan bien el inglés, como quienes terminaron su educación secundaria en Colombia y migraron pero no continuaron sus estudios profesionales allí y su nivel de inglés era intermedio o bajo.
} 
Sin embargo, su experiencia política o sindical previa en Colombia les permitió percibir estas vivencias como casos de discriminación y de vulneración de derechos, no solo en tanto migrantes colombianos, sino como un tipo de discriminación compartida con otros grupos latinos con estatus migratorio irregular y con poco dominio del inglés. Es por ello frecuente encontrar testimonios que evidenciaban la percepción de dichos fenómenos de discriminación. David, un líder sindical en el área, señaló:

La discriminación [es frecuente] en los trabajos [...] Los trabajadores son muy pobres, con muy bajo nivel educativo, casi sin educación, no requieren ninguna capacitación para el trabajo porque son los más baratos, los que pagan más mal. Hay muchas empresas que utilizan que -suena increíble pero sucede-, aquí me ha tocado demandar empresas que le pegan a sus empleados, no les pagan lo que trabajan, aquí si tú trabajas 40 horas en una semana después de esas 40 horas les tienen que pagar a tiempo y medio pero muchos de ellos simplemente no reclaman porque como son indocumentados, por miedo, no pueden hacerlo (David, 2011).

Al tiempo, muchos de los migrantes movilizados a favor de la defensa de los derechos humanos en Colombia percibieron que el Estado veía a los migrantes solamente como generadores de remesas y como lobby político prointereses de la institucionalidad. Sin embargo, debido a que en Colombia algunos de ellos habían afrontado la estigmatización por su labor sindical, de defensa de derechos humanos y de oposición política, optaron por aprovechar el ambiente político de la ciudad de Nueva York. De este modo, se vincularon con organizaciones y actores alternativos a las organizaciones estatales de origen y destino (por ejemplo, sindicatos y organizaciones prodefensa de derechos humanos) para visibilizar las violaciones de Derechos Humanos que tienen lugar en Colombia.

En efecto, estos migrantes también se encontraron con el ambiente político más liberal y más diverso en materia sociocultural ofertado principalmente por la ciudad de Nueva York (en comparación con el resto de Estados Unidos), en donde los sindicatos juegan un rol político importante $-\mathrm{y}$ son apoyados por el partido demócrata-, los grupos políticos de izquierda gozan de visibilidad y de influencia en el contexto político de la ciudad y se cuenta con medios de comunicación alternativos y con organizaciones de defensa de derechos humanos. Entonces, en medio de este ambiente político, y a partir de su experiencia política previa y su orientación política, contaban con mayores oportunidades para la creación de vínculos con sectores demócratas y organizaciones sindicales y de defensa de derechos humanos.

Ante esta situación, muchos de ellos dirigieron su búsqueda de reconocimiento hacia las organizaciones no gubernamentales existentes en la ciudad de Nueva York enfocadas en la defensa de derechos humanos, al tiempo que hacia los grupos políticos de izquierda en Colombia, combinando así la participación en el contexto local con la participación en el país de origen. De este modo, integraron la difusión de información relacionada con las violaciones de derechos humanos en Colombia con las movilizaciones por la defensa de derechos humanos en el contexto local (como por ejemplo, movilizaciones por el derecho a 
la ciudad y la vivienda digna para las comunidades migrantes latinas).

Se destaca en este sentido, la participación de varios migrantes colombianos en sindicatos locales, gracias a los cuales obtuvieron el apoyo para combinar un enfoque local con uno transnacional, movilizaron recursos y actores, financiaron la visita de diversos líderes sindicales colombianos a la ciudad de Nueva York, apoyaron la participación de líderes políticos del contexto local de Queens en actividades sindicales en Colombia, y participaron incluso en la creación de organizaciones de defensa de los derechos de las comunidades latinas en el área. Por ejemplo, algunos de estos migrantes vinculados activamente en sindicatos de la ciudad de Nueva York participaron en el ańo 2005 en la creación del Comité de Solidaridad con los sindicalistas en Colombia que -pese a su reducido número de integrantes- gestionó el apoyo de sindicatos y de diversas ONG en Estados Unidos para vincular los intereses sindicales de Colombia con los de los trabajadores latinos en Estados Unidos, enlazando las temáticas de su país de origen con el contexto local de la ciudad de Nueva York. Así, promovieron la visita de dirigentes sindicales colombianos, líderes políticos de Queens a Colombia y el apoyo a las campańas políticas colombianas de candidatos de izquierda en la ciudad de Nueva York. Esto con el fin de fortalecer las alianzas políticas con los sectores de izquierda a nivel transnacional y contar con el apoyo de los líderes sindicales en Nueva York, en las campañas de los políticos locales.

Aunque en estos migrantes la noción de identidad colombiana estaba presente (en tan- to difundían información sobre la situación de derechos humanos en el país de origen), esta logró ampliarse hacia una identidad panétnica, latina, pues identificaron muy pronto la importancia de entablar alianzas con otros migrantes latinoamericanos para buscar apoyos en su movilización prodefensa de los derechos humanos. Al decir de Alfonso, uno de los líderes sindicales entrevistados en el área: "Yo voy a donde se celebra la hispanidad en mi sindicato que es manejado por puertorriqueños, empezamos a visitar sindicatos y como somos sindicalistas nos reciben bien, entonces no estamos criticándolos [...] Los dirigentes de esos sindicatos nos ayudan, nos acogen" (Alfonso, 2011).

\section{EL LIDERAZGO POLÍTICO TRANSNACIONAL DE LOS MIGRANTES COLOMBIANOS EN RELACIÓN CON LA BÚSQUEDA DE RECONOCIMIENTO}

Los líderes políticos transnacionales colombianos de las áreas consideradas, no fueron ajenos a las dinámicas de búsqueda de reconocimiento social señaladas en el apartado anterior. Debido a la fragmentación y polarización de esta comunidad predominó en ellos la búsqueda de reconocimiento a nivel individual, la cual orientaron hacia diversos actores del campo político transnacional. Dichas estrategias de búsqueda de reconocimiento variaron en relación con las particularidades del contexto y sistema político en cada una de estas localidades, su experiencia política previa, su orientación político-ideológica y su procedencia regional. Factores como la generación y los cambios en el 
capital económico, social y cultural no incidieron de modo determinante en estas estrategias.

Por un lado, durante el periodo considerado algunos líderes, principalmente en la ciudad de Nueva York (Queens, particularmente en los distritos 21 y 25$)^{14}$, orientaron su búsqueda de reconocimiento hacia la institucionalidad colombiana, movilizando una fuerte identidad nacional, siendo reticentes a formar alianzas latinas e involucrándose muy poco -e incluso estando al margen de- en la maquinaria política demócrata. Estos líderes presentaban una orientación política ubicada en el espectro centro-derecha-derecha, poca o nula experiencia política previa, eran migrantes anteriores a la década de los noventa, procedentes en su mayoría del interior del país.

Debido a que la ciudad de Nueva York es grande y diversa, su sistema político hace que la contienda electoral sea esencial para obtener cargos de representación política formal en Queens y, por consiguiente, que para triunfar en ella sea necesario establecer alianzas políticas a nivel latino. Sin embargo, considerando la procedencia regional de los migrantes colombianos de los distritos 21 y 25 de Queens, estos movilizaron una fuerte identidad nacional colombiana, y reprodujeron ciertas formas del racismo cultural existentes en Colombia frente a los migrantes provenientes de las zonas costeras, percibiendo a las comunidades dominicanas y puertorriqueńas - principalmente- como lejanas en términos culturales, limitando el contacto (cuando de actividades voluntarias y "tiempo libre" se trata) y, por consiguiente, su identificación como parte del mismo grupo cultural. Esto los llevó a ser reticentes a formar alianzas latinas y a involucrarse muy poco con la maquinaria política demócrata. Aquí también influyó su orientación política, más cercana -según el decir de algunos de estos líderes- al partido republicano, el cual no tiene opciones de juego en Queens ante el peso absoluto de la maquinaria demócrata en este condado, al punto de monopolizar candidaturas y nombramientos. Esta cercanía ideológica con el partido republicano fue ratificada en diversos testimonios, entre ellos, el de Roberto, un dirigente comunitario en la ciudad de Nueva York:

Ellos creen que los estoy insultando pero yo solo les digo la verdad [...] Como latinos, no como colombianos o dominicanos, tengamos una agenda definida, por eso insisto en que hay que tener un partido latino, si no, apoderémonos del partido republicano, pero creo que en el fondo somos eso, porque no estamos a favor del aborto, tenemos muchas cosas conservadoras, pero va a ser la voz del partido de nosotros (Roberto, 2011).

En consecuencia, buena parte de estos líderes orientó su búsqueda de reconocimiento hacia la institucionalidad colombiana. Así, para

14 Los cuales presentan gran cantidad de población latina, en su mayoría de origen caribeño. Además, para 2000-2010 los líderes del distrito 21 del Consejo Municipal -creado después del censo de 2000- eran de origen latino (dominicano, puertorriqueño y ecuatoriano), así como los líderes del distrito 39 de la Asamblea del estado de NY (Corona, Elmhurst y Jackson Heights) y del distrito 13 en el senado del estado de NY (Corona, Elmhurst, Jackson Heights y Woodside). 
muchos de ellos recibir un apretón de manos de parte de los políticos colombianos significaba un reconocimiento público de su apoyo y ser tenido en cuenta como un representante destacado de la comunidad colombiana. Con frecuencia mencionaron su favorabilidad frente a la institucionalidad colombiana -en particular, frente al Gobierno Uribe- y su orgullo por haber conocido y recibido una mención o felicitación a su labor por parte de este. Por ejemplo, Jorge, un líder político del área norte de Nueva Jersey, señaló al respecto: "Me tocó trabajar bastante con Álvaro Uribe que tuvo dos elecciones, él me hizo el honor de venir aquí al festival [de la Independencia colombiana de Hackensack], ;Ese fue un honor tremendo!" (Jorge, 2011).

Por otro lado, en el área norte de Nueva Jersey (Hackensack), principalmente, se dio el caso de líderes con orientación política de centro-derecha-derecha, elevada experiencia política previa en organizaciones partidistas regionales y de base en Colombia, migrantes con anterioridad a la década de los noventa como primera generación o como generación 1.5 y procedentes -en su mayoría- de la costa caribe. Estos llegaron a una localidad en donde la colonia colombiana en su mayoría era costeña y contaron además con una organización sociocívica regional (Club Colombia Hackensack). Dicho perfil de líder migrante dispuso además de un capital social que se extendía a la población latinoamericana residente en dicha localidad. Debido a su procedencia regional, estos líderes percibieron su cercanía cultural con otros migrantes caribeños (dominicanos, puertorriqueńos y cubanos en el área norte de Nueva Jersey), se identificaron rápidamente con ellos y ampliaron su noción de identidad latina (de línea "caribe"). Esto hizo posible y deseable en ellos el establecimiento de alianzas latinas y su vinculación con el partido demócrata. A este factor cabe agregar el de la experiencia política previa de algunos de estos líderes en organizaciones partidistas regionales y de base en Colombia. Así pues, muchos de los entrevistados conocían y valoraban la importancia de las alianzas políticas para acceder a cargos de poder local ${ }^{15}$.

En adición a lo anterior, la búsqueda de reconocimiento de estos líderes en el partido demócrata, fue combinada por algunos de ellos -principalmente por los de primera generación-con la búsqueda de reconocimiento en la institucionalidad colombiana. De este modo, uno de los líderes más destacados en Hackensack participó como candidato al Senado en las elecciones de 1998. Al igual que en el caso de los líderes de Queens, para estos dirigentes recibir un apretón de manos de parte de los políticos colombianos implicaba un motivo

15 Por ejemplo, Jesús Galvis fue cofundador del Club Colombia Hackensack y desde los ańos ochenta ayudó a crear la Latin American Association y el Hispanic USA. Allí se involucró con los políticos republicanos y demócratas y participó en las campańas por la doble ciudadanía en los años noventa. En 1992, participó en el Concejo de Hackensack; en 1996, en la creación de la Latin American Democratic Association (LADA), organización orientada a empoderar y apoyar latinos para cargos en el condado de Bergen. Después participó en la American, Latin Civic Association (ALCA), orientada a promover el liderazgo político latino. 
de orgullo en tanto reconocimiento público de su apoyo.

Pese a ello, la búsqueda de reconocimiento orientada hacia el partido demócrata y hacia otros actores de la política doméstica norteamericana también tuvo lugar en la ciudad de Nueva York. Se dio principalmente por parte de líderes colombianos de generación 1.5 y de segunda generación que obtuvieron la posición de líderes de distrito por el partido demócrata ${ }^{16}$. Este es un cargo ad-honorem, por un periodo de dos años, encomendado principalmente de servir de bisagra articuladora entre el partido demócrata y la comunidad del distrito ${ }^{17}$. Estos líderes manejaban un inglés fluido, contaban con un capital social que trascendía la comunidad colombiana y comprendieron la importancia de establecer alianzas latinas, de dejar de lado una orientación exclusivamente colombianista y de vincularse en la maquinaria política demócrata.

\section{CONCLUSIONES}

Este artículo ha querido contribuir al estudio del transnacionalismo político de los colombianos en la ciudad de Nueva York y el área norte de Nueva Jersey, desde la óptica del reconocimiento, durante el periodo 1990-2010.
Se sostuvo que, con el fin de abordar de una manera más completa el transnacionalismo político de estos migrantes, debe ponerse el lente no solo sobre las prácticas políticas formales e individuales (entiéndase aquí la participación en comicios electorales del país de llegada y de origen), sino además sobre las prácticas políticas no electorales o informales y los procesos colectivos. Esto por considerar que centrar la mirada en la participación política electoral dejaría de lado a aquellos migrantes colombianos que por distintas razones (como la carencia de doble ciudadanía o de cierto capital económico, social, cultural o estatus migratorio que les permita dedicar el tiempo para estar enterados de la política colombiana o norteamericana y entenderlas) no participan formalmente en política.

Buena parte de estos migrantes afrontaron experiencias de estigmatización en los contextos de origen y de llegada que les generaron -especialmente a quienes presentaban mayor vulnerabilidad económica y de etatus legal, cultural y social- una confusión respecto de su identidad y fuertes sentimientos de inseguridad al afectar tanto su autocomprensión como su valor social en tanto individuos y grupo. Con ello, se corroboró la vigencia interpretativa de los planteamientos de Axel Honneth que destacan la estrecha relación entre individuación y

16 En 2000, el colombiano William Salgado obtuvo el cargo de líder de distrito por el partido demócrata y solo diez años más tarde otra persona de ascendencia colombiana -Jessica Ramos- ocupó dicho cargo.

17 El líder está encargado de escuchar a los miembros del partido registrados en el distrito para saber qué temas afectan su calidad de vida, y asegura que estos temas sean conocidos por parte de los funcionarios electos del distrito, estatales y federales del partido. A la vez, informa a los miembros del partido registrados del distrito en materia de candidatos, programas y resultados electorales. 
reconocimiento intersubjetivo. Se confirmó además la riqueza de estos planteamientos para una comprensión del transnacionalismo político colombiano en relación con las heridas identitarias generadas en los migrantes con las experiencias de discriminación y exclusión en origen y destino, y con la búsqueda de reconocimiento social como alternativa para reconstruir su integridad.

En el contexto de origen, estos migrantes afrontaron experiencias de desprecio moral vinculadas a polarización social y política. Así, muchos experimentaron marginación social por cuenta de la inequidad y las barreras para su movilidad social ascendente y la de sus familias. Otros migrantes experimentaron el deterioro de la situación política y la generalización de las violencias con el consecuente aumento de la inseguridad. Ahora bien, en el contexto de llegada, los migrantes fueron estigmatizados en tanto latinos, hispanoparlantes y narcotraficantes. Los inmigrantes en situación de irregularidad y los residentes permanentes afrontaron privación de derechos y marginación social, aún más si contaban con un escaso capital cultural, un pobre manejo del idioma inglés y un acento muy marcado. Adicionalmente, a su llegada a Estados Unidos, los migrantes percibieron que el Estado colombiano los veía simplemente como generadores de remesas y de lobby político a favor de los intereses de la institucionalidad.

Frente a las prácticas políticas transnacionales y al liderazgo político transnacional que dichos migrantes desplegaron como estrategias de búsqueda de reconocimiento social, se encontró que -durante el periodo 1990-2010buena parte de estos migrantes orientó su búsqueda de reconocimiento hacia las prácticas políticas transnacionales de carácter informal y colectivo que trascendían el voto. Así, participaron en organizaciones colombianas, aprovechando con ello su capital social o buscando incrementarlo. Estas prácticas representaron para ellos una mayor autonomía, pues les permitieron participar en los contextos de origen y destino sin tener que "naturalizarse" o votar.

Podría pensarse que con su migración, $\mathrm{y}$ al estar alejados del contexto colombiano y de sus violencias, los colombianos superarían la polarización política y las fragmentaciones existentes en el país de origen, logrando acciones políticas concertadas. Pero, algunos factores (como la desconfianza generada por el estigma del narcotráfico, el clasismo y regionalismo, la polarización social y política, así como las huellas del conflicto) incidieron para que las organizaciones generadas por los migrantes reprodujeran la fragmentación existente en Colombia. De este modo, estas terminaron operando en dos grandes niveles: 1) apoyo a iniciativas del Gobierno colombiano y lucha contra el estigma del narcotráfico y la violencia, y 2) apoyo a iniciativas de defensa de derechos humanos.

Ahora bien, cabe señalar que los líderes de las áreas consideradas no fueron ajenos a las dinámicas de búsqueda de reconocimiento social seńaladas previamente. Debido a la fragmentación y polarización de la comunidad colombiana, predominaron en ellos las estrategias de búsqueda de reconocimiento a nivel individual, las cuales variaron en relación con la localidad de llegada (y las particularidades del contexto y sistema político), su experiencia 
política previa, orientación político-ideológica, procedencia regional, generación y capital económico, social y cultural.

\section{REFERENCIAS}

Aleinikoff, T. (2001). Policing Boundaries: Migration, Citizenship and the State. En Gerstle, G. y Mollenkopf, J. E Pluribus Unum? Contemporary and Historical Perspectives in Immigrant Political Incorporation. New York: Rusell Sage Foundation.

Ansart, P. (1990). Les sociologies contemporaines. Paris: Points.

Arango, J. (2003). La explicación teórica de las migraciones: luz y sombra. Revista Migración y Desarrollo (001). Recuperado de http://pendientedemigracion.ucm.es/info/gemi/descargas/ articulos/42ARANGO_La_Explicacion_Teorica_Migraciones_Luces_Sombras.pdf

Bidegaín, A. M. y Aysa, M. (Coords.) (2006). Cuantificación y caracterización de la población inmigrante colombiana en los Estados Unidos. Bogotá: Ministerio de Relaciones Exteriores de Colombia.

Bourdieu, P. (1997). Razones prácticas. Sobre la teoría de la acción. Barcelona: Anagrama.

Cardenas, M. y Mejia, C. (2006). Migraciones Internacionales en Colombia: ¿Qué sabemos? Estudio preparado para la CEPAL, en una iniciativa regional coordinada por Andrés Solimano. Recuperado de: http://www10.iadb.org/intal/intalcdi/ pe/2009/02989.pdf

Castles, S. (2004). Nation and Empire: Hierarchies of Citizenship in the New Global Order. International Politics, 42, 203-224.

Cordero Guzmán, R., Smith, C. y Grosfoguel, R. (2001). Migration, Transnationalism and Race in a Changing New York. Philadelphia: Temple University Press.

Díaz, L. M. (2008a). Olvidados y ofendidos: esbozo histórico de la migración internacional colombiana. Revista Desde la Región (50), 15-28.

Díaz, L. M. (2008b). Políticas migratorias de Colombia y Ecuador en el marco de la crisis global. En Diálogos Migrantes. Bogotá: Fundación Esperanza.

Echeverri, M. (2010). "Son diez horas de viaje y cinco años que te meten encima”. Proyectos, identidades y vinculos transnacionales de los y las jóvenes colombianas en España. Madrid: Universidad Computense de Madrid.

Fraser, N. y Honneth, A. (2006). ¿Redistribución o reconocimiento?: un debate politico-filosófico. Madrid: Ediciones Morata S.L.

Goffman, E. (2008). Estigma: identidad deteriorada. México: Paidos editorial.

Gómez, M. (2006). Ni chicha ni limonada. El transnacionalismo político colombiano. En Bidegaín, A. M. y Aysa, M. (coords.). Cuantificación y caracterización de la población inmigrante colombiana en los Estados Unidos: sistematización general y estado del arte (pp. 12-152). Bogotá: Ministerio de Relaciones Exteriores de Colombia.

Grosfoguel, R. (2007a). Migrantes coloniales caribeños en los centros metropolitanos del sistema-mundo: los casos de Estados Unidos, Francia, los Países Bajos y el Reino Unido. Migraciones CIDOB.

Grosfoguel, R. (2007b). Latinos(as) y la descolonización del imperio estadounidense en el siglo XXI. Bogotá: Tabula Rosa Editores.

Grosfoguel, R. (2013). Colonialidad del poder y dinámica racial: notas para la reinterpretación de los latinocaribeños en Nueva York. En Grosfoguel, R. Sujetos Coloniales. Una perspectiva global de las migraciones caribeñas. Nueva York: Abya-Yala/ UPS Publicaciones. 
Guarnizo, L., Sánchez, A. y Roach, E. (1999). Desconfianza, solidaridad fragmentada y migración transnacional: los colombianos en la ciudad de Nueva York y Los Ángeles. México: Paidos.

Guarnizo, L. (2001). On the political participation of transnational migrants: old practices and new trends. En Gerstle, G. y Mollenkopf, J. E Pluribus Unum? Contemporary and Historical Perspectives in Immigrant Political Incorporation, Russe. New York: Rusell Sage Foundation.

Guarnizo, L. (2004). La migración transnacional colombiana: implicaciones teóricas y prácticas. En Ministerio de Relaciones Exteriores. Memorias Seminario sobre migración internacional colombiana y la conformación de comunidades transnacionales. Bogotá: Ministerio de Relaciones Exteriores.

Guarnizo, L. (2006). Migración, globalización y sociedad: teorías y tendencias en el siglo XX. En Ardila, G. (2006). Colombia: migraciones, transnacionalismo y desplazamiento (pp. 65-126). Bogotá: Centro de Estudios Sociales (CES). Universidad Nacional de Colombia, Facultad de Ciencias Humanas.

Guarnizo, L. (2007). El Estado y la migración global colombiana. Migración y Desarrollo.

Guarnizo, L. (2006a). Migración, globalización y sociedad: teorías y tendencias en el siglo xx. En Ardila, G. Migraciones, transnacionalismo y desplazamiento. Bogotá: Norma.

Honneth, A. (1992). Integridad y desprecio. Motivos básicos de una concepción de la moral desde la teoría del reconocimiento. Revista Isegoría (5), 78 92. Recuperado de: http://isegoria.revistas.csic.es/ index.php/isegoria/article/viewArticle/339

Honneth, A. (1999). Reconocimiento y obligaciones morales. Revista de Estudios Políticos (14), 173-187.

Irizarry, S. (2001). Deceptive solidity: public signs, civic inclusion and language rights in Nueva York City.
En Lao Montes, A. Y. The Latinization of New York City. México: Columbia University Press.

Jones-Correa, M. (1999). Between Two Nations. The Political Predicament of Latinos in New York City. New York: Cornell University Press.

Massey, D. y Sánchez, M. (2010). Brokered Boundaries. New York: Rusell Sage Foundation.

Múnera, L. (2005). Poder (trayectorias teóricas de un concepto). Revista Colombia Internacional, 62, 32-49. Recuperado de: http://colombiainternacional.uniandes.edu.co/view.php/466/index. php?id=466

Lao-Montes, A. (2001). Mambo Montage: The Latinization of New York City. New York: Columbia University Press.

Portes, A. (2004). El desarrollo futuro de América Latina. Neoliberalismo, clases sociales y transnacionalismo. Bogotá: Publicaciones ILSA.

Portes, A., Guarnizo, L. y Landolt, P. (2003). El estudio del transnacionalismo: peligros latentes y promesas de un campo de investigación emergente. En Portes, A. y Guarnizo, L. Y. La globalización desde abajo: transnacionalismo inmigrantes y desarrollo. La experiencia de Estados Unidos y America Latina. México: Porrúa.

Portes, A. y Escobar, C. (2006). Immigrant Transnational Organizations and Development: a Comparative Study. Princeton University: The Center for Migration and Development Working Paper Series.

Portes, A. y Rumbaut, R. (2006). Immigrant America. A portrait. California: University of California Press.

Ribas, N. (2004). Una invitación a la sociología de las migraciones. Barcelona: Ediciones Bellaterra. 
Sanjek, R. (2000). The Future of Us All: Race and Neighborhood Politics in New York City. New York: Cornell University Press.

\section{Artículos de prensa/Boletines}

Census Bureau’s American Community Survey (2007). Boston.

Center for Latin American, Caribbean y Latino Studies (CLACS) (2010). The Latino population of Nueva York City.

Labor Market Views (2010). Recuperado de: http://lwd. dol.state.nj.us/labor/lpa/pub/lmv/lmv_14.pdf

Pew Hispanic Center (2010). Hispanics of Colombian Origin in the United States. Recuperado de: http://www.pewhispanic.org/2012/06/27/ hispanics-of-colombian-origin-in-the-unitedstates-2010/

US Census Bureau. (2011). Overview of Race and Hispanic Origin: 2010, Census Briefs. Recuperado de: http://www.census.gov/prod/cen2010/briefs/ c2010br-02.pdf

\section{Entrevistas citadas}

Alfredo (2009). Entrevista realizada en Queens, ciudad de Nueva York, junio.

Sergio (2010). Entrevista realizada en Queens, ciudad de Nueva York, julio.

Alfonso (2011). Entrevista realizada en Queens, ciudad de Nueva York, junio.

Fabio (2011). Entrevista realizada en Brooklyn, ciudad de Nueva York, junio.

Hernán (2011). Eentrevista realizada en Queens, ciudad de Nueva York, junio.

Pecas (2011). Entrevista realizada en Hackensack, área norte de Nueva Jersey, junio.

Rebeca (2011). Entrevista realizada en Queens, ciudad de Nueva York, junio.

Roberto (2011). Entrevista realizada en Queens, ciudad de Nueva York, junio.

Rodolfo (2011). Entrevista realizada en Queens, ciudad de Nueva York, junio.

Esmeralda (2011). Entrevista realizada en Queens, ciudad de Nueva York, junio.

Maria Clara (2011). Entrevista realizada en Queens, ciudad de Nueva York, junio.

David (2011). Entrevista realizada en Hackensack, área norte de Nueva Jersey, julio.

Derly (2011). Entrevista realizada en Hackensack, área norte de Nueva Jersey, julio.

Ignacio (2011). Entrevista realizada en Union City, área norte de Nueva Jersey, julio.

Jorge (2011). Entrevista realizada en Hackensack, área norte de Nueva Jersey, julio. 